\title{
Andreia Duarte*
}

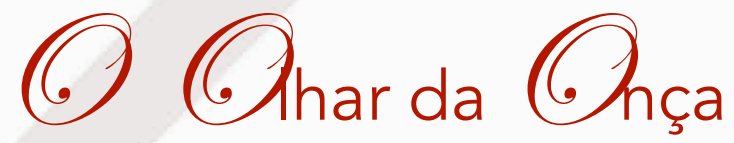

\section{Percursos da Experiência}

Tre Qfook of Qunce

\section{Experience Ways}




\section{RESUMO}

A presente escrita busca apresentar e reconhecer a experiência como forma de pensar e fazer dentro da Arte da Cena, no intuito de convidar a uma reflexão sobre a possibilidade de relação entre a questão indígena e o teatro. Assim, apresenta um percurso próprio que se deu durante 18 anos de vivência, pesquisa e criação artística, reconhecendo o caminho que estimulou a investigação, as transformações e os resultados que trouxeram novas fissuras. Em todo o momento havia o desejo por um teatro que valoriza a autonomia do ator enquanto criador, na busca de construir uma cena poéticapolítica. É relevante dizer que a conjuntura conceitual e prática foi feita no diálogo com - saber Kamayura, de líderes indígenas brasileiros, na discussão da corporeidade, no embasamento do estudo da performance e sobre a noção de experiência.

Palavras-chave: indígena; colonização; corporeidade; experiência; atoral.

\section{ABSTRACT}

The present paper seeks to present and recognize the experience as a way of thinking and doing within the Scene Art, in order to invite a reflection on the possibility of a relationship between the indigenous issue and the theater. Thus, it presents a course that has taken place during 18 years of experience, research and artistic creation, recognizing the way that stimulated research, transformations and results that brought new fissures. At all times there was a desire for a theater that value the autonomy of the actor as creator, in the quest to construct a poetic-political scene. It is relevant to say that the conceptual and practical conjuncture was made in the dialogue with the Kamayura knowledge, of Brazilian indigenous leaders, in the discussion of corporeity, on the basis of performance studies and on the notion of experience.

Keywords: indigenous; colonization; corporality; experience; actor. 


\section{O CONVITE}

Durante os vários anos que venho relacionando o teatro e o conhecimento dos povos chamados índios ${ }^{i}$, por meio de um investimento pessoal, teórico e prático como atriz, reiteradamente eu percebo a existência de certos estranhamentos sobre a pesquisa e por parte de colegas dos dois campos. É como se houvesse uma distancia sobre o entendimento de como essas duas realidades podem ser conectadas de forma aprofundada em uma investigação. Com essa percepção, eu começo a questionar se na verdade sou eu que não estou conseguindo comunicar de adequadamente sobre o que envolve essa tarefa. Ou seja, como eu estou pensando a pesquisa? Quais foram os caminhos que me levaram para essa reflexão? Porque ela é importante dentro desses campos? Porque eu escolhi um percurso e não outro? Quais parâmetros estão sendo escolhidos como base deste estudo?

Em um sentido de aproximar e compartilhar é que eu faço esta escrita, pensando-a como possibilidade de convite para o diálogo e o encontro sobre as relações entre as questões indígenas e o teatro. Mas também, como forma de organizar o pensamento e apresentar uma pesquisa que valoriza a experiência dentro das artes da cena. Para que isso possa tornar possível, é importante dizer que estarei trabalhando com referências da própria vida, visto que morei cinco anos com o povo Kamayura no Parque Indígena do Xingu ${ }^{\mathrm{ii}}$, construindo uma relação de dezoito anos até a atualidade. E que durante este tempo, aprofundei em uma investigação atoral e sobre 
o corpo indígena que reconheço nos meus processos de formação, criação e investigação: realizei prática como atriz, produção de cena, mestrado em Artes (EBA/UFMG) ${ }^{\mathrm{iii}}$, procedimento de ensino, o solo Gavião de duas cabeças ${ }^{\text {iv }}$ e agora estou no Doutorado fazendo parte do programa de Artes Cênicas da Universidade de São Paulo.

Portanto, o trabalho não separa empenho individual, acadêmico ou mesmo artístico; ao contrário, assume o percurso da existência, traçando-o, indagando-o, para levantar discussão. Esta atitude está apoiada nos estudos da performance que entende o aprendizado e a transmissão de conhecimento por meio da ação incorporada e das escolhas que se fazem. Como explica Diana Taylor (2002, p 88), para este campo teórico a performance é percebida como uma episteme, um modo de conhecer e não simplesmente como objeto. E completa: "ao me situar como mais um ator social nos roteiros que analiso, espero posicionar meu investimento pessoal e teórico na minha argumentação. Escolhi não encobrir as diferenças de tom, mas colocá-las em diálogo com que eu sou e o que faço". Amparada nesse entendimento que a experiência é inserida como referência, dialogando a todo momento com um teatro que tem a sua ênfase no "fazer", na valorização do processo e pode ser percebido como a pesquisa cênica das realidades sociais do outro e a interrogação dos muitos territórios da alteridade e da exclusão social no país (FERNANDES, 2008, p 19). 
Nesse contexto conceitual e da prática, também no diálogo com o conhecimento Kamayura, de líderes do movimento indígena brasileiro, como Ailton Krenak e Davi Kopenawa, sobre a noção de experiência a partir de Jorge Larossa (2015), sobre as discussões que envolvem a corporeidade, colonização e performance ${ }^{\mathrm{v}}$ que passo a descrever a trajetória que envolve o pensamento dessa investigação cênica.

\section{ENTÃO, QUAL É O PONTO DE VISTA, CARAIPvi?}

Convidada no início do ano de 2018, para fazer uma aula/palestra em uma escola de teatro da cidade de São Paulo, para seus coordenadores e orientadores, e sobre as conexões entre o teatro e a causa indígena, comecei a fala me apresentando e dizendo que para entender um pouco mais o contexto escolar no qual eu estava inserida, seria interessante saber quantos daqueles profissionais de teatro já tinham tido contato com algum indígena ou mesmo se poderiam me dizer o nome de etnias que conheciam ou já tinham ouvido falar. Um professor contou sobre uma pesquisa teatral que participou com os Suruí, outro comentou que tinha assistido um filme sobre os Krahô e, ainda, um participante disse que conhecia os Guarani que moram na proximidade da cidade de São Paulovii. Não surpreendente, as quase 30 pessoas que estavam na sala não chegaram a denominar dez etnias do território brasileiro. Claro que sei que este fato não é um "privilégio" apenas deste grupo. Quando retomo o próprio discurso no primeiro capítulo do 
mestrado, vejo a seguinte fala descrevendo um dos motivos que me levou para a aldeia no ano de 2001, aos 21 anos: "(...) eu queria entender esses povos originários do Brasil e que até então eram distantes para mim, pois eu não havia obtido informações além de pitorescas, superficiais e preconceituosas sobre os mesmos (FIGUEIREDO, 2015, p 29)".

Sabendo dessa comum ausência de conhecimento, continuei a discussão explicando que nós temos um censo que declara a existência de 305 etnias indígenas no Brasil que falam

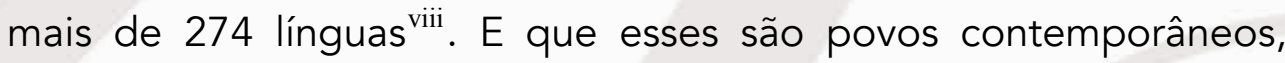
remanescentes diretos do processo de colonização, que em sua particularidade sociocultural resistem e existem a diferentes situações de genocídio, injustiça, marginalização e ataques desde 1500. E levantei a seguinte pergunta: com toda essa conjuntura histórica, porque a sociedade brasileira em geral ainda desconhece, ou mesmo, se posiciona tão afastada dessas etnias?

Dentre as várias reflexões colocadas, um professor argumentou se não seria o fato de eles (os povos indígenas) não morarem na cidade, mas sim em zonas rurais? Eu respondi que o ponto de vista geográfico não justificaria a falta de saber sobre os povos originários, até porque, segundo o censo, a população indígena habita tanto as áreas rurais como urbanas e estão em todos os estados do Brasil $^{\mathrm{ix}}$. Mas também enfatizei, que a distância pode ser entendida de forma relativa e a partir de onde nos colocamos. Por exemplo, se o meu corpo está localizado no centro 
da cidade de São Paulo, eu posso dizer que a periferia extrema está distante de mim. Mas se eu me coloco localizada na periferia, o oposto também pode ser afirmado. E isso vale para qualquer noção de intervalo entre um lugar e outro.

De qualquer forma, estar longe de um território nunca foi impedimento para que brasileiros pudessem conhecer outras formas de vida e fazer intercâmbios em diferentes regiões do país ou mundo. Ao contrário, o que estava sendo revelado era que essa concepção de longitude não era na verdade espacial. Mas que esse "não saber" sobre a existência indígena é consequência de um processo longo de apagamento das identidades territoriais, das referenciais culturais e linguísticas das populações originais. E essa é uma reflexão que considero central para falar de como começo a pensar a pesquisa indígena no campo teatral. $O$ fato de eu perceber que essa invisibilidade é consequência da estratégia de poder na formação do Brasil, que desde o período colonial seleciona e legitima conhecimentos em detrimento de outros, me trouxe uma imensa indignação e foi motivação para eu tentar aprofundar, com rigor, sobre os conhecimentos dos povos indígenas.

Diferente da história oficial transmitida nas escolas, por meio dos livros didáticos autorizados, vejo outra perspectiva de ocupação e entendimento do território, quando rememoro, por exemplo, a fala do falecido Tacumã Kamayura, grande pajé e pai do cacique da aldeia Kamayura, contando com a ação de apontar o dedo para o norte do rio Xingu e depois (ainda com o dedo) mapear no chão de 
terra o percurso que seguiram, mostrando como eles caminharam no norte do Brasil com os índios Tapirapé, depois adentraram na região do baixo rio denominando o local de Diauarum (atualmente posto indígena da Funai, porém "lugar de onça" na tradução dos Kamayura), subiram atravessando confluências de rios em zonas sagradas como a terra Morená, penetraram por regiões reveladas em suas próprias mitologias para finalmente estabelecerem onde, segundo fontes não indígenas, foram encontrados pela primeira vez "junto à bela margem arenosa de uma laguna" (STEINEN, 1894, p. 148-151 in SAMAIN, 1991, p. 43) ${ }^{\mathrm{x}}$. Sobre essa lagoa, Tacumã contava:

Essa lagoa era aldeia, na época não tinha lagoa, essa que está aqui, a lagoa, era aldeia Mawajaka [...] Aquele lugar lá chama Jamutukuri, tem esse nome porque lá tinha muito gafanhoto. Outro chama Nu'wuijari, porque lá tinha muita abelha, quem morava lá era Waurá. [...] Aquela beira chama Jawara tymap, porque a onça que comeu a pessoa foi enterrada lá. Esse aqui, onde o pessoal banha chama Morojuka tawet porque a pessoa morreu lá. Aquele lá chama Turu'a rape, porque lá [...] era caminho do espírito Turu'a rape. Hoje não tem mais, faz tempo a gente escutava toda tarde Turu'a, toda tarde eles gritavam. [...] outro também chama ljuara juru porque é buraco de cobra, antigamente a cobra saía de lá, nossos bisavôs olhavam a cobra saindo e atravessando a lagoa. [...] depois Amu'ata ry porque lá tinha muito cascudinho, depois tem Yarape, caminho da canoa, depois chega em My'yta, nossos bisavôs usavam muito aquele lá para pescaria [...] (KAMAYURA e KAMAYURA, 2013, p. 202).

Ouvir todo esse conhecimento da oralidade de Tacumã, um saber corporal e vivido, faz reconhecer lugares de memória, de saber geográfico, por onde fugiram de tribos guerreiras inimigas, 
por onde sobreviveram relacionando-se com o ambiente local, entre si, em uma organização familiar, com outros povos amigáveis. Possibilita perceber uma construção de identidade, na qual a experiência daquele povo foi sendo elaborada e formando toda dinâmica cultural que faz os Kamayura ser quem eles são até atualidade.

Se pensarmos do ponto de vista da história oficial, aquele território contado por Tacumã era pretendido por projetos governamentais de expansão demográfica e econômica no centrooeste brasileiro. Por isso promulgado como terra distante, espaço vazio a ser conquistado por desbravadores em benefício à pátria e para ser ocupado ${ }^{\mathrm{xi}}$. Como nos conta Villas Boas (1994, p. 613) sobre a posição do Estado em relação a campanha de quase dez anos para formação do Parque Indígena do Xingu xii , "a União nem se dava o trabalho de examinar. Não havia porque perder tempo, pensou-se em mutilar o Estado para atender essa gente estranha, pelada sem direito a voto, só porque havia quem dissesse que eles andavam por cá há dezenas de milhares de anos". Mas se nos colocarmos do ponto de vista do grande pajé, aquele é local sagrado, pertencente ao originário, no qual o Mawutsinin criou o mundo, os cauaip ${ }^{x i i}$, os caraip, onde o Sol e o Lua inventaram a morte e realizaram o Kwaryp - ritual de luto a ser assumido por famílias que desejam homenagear o ente falecido ${ }^{\text {xiv }}$. Como sempre ouvi a fala do cacique Kotok Kamayura: "essa terra é onde eu 
mamei no seio da minha mãe, onde o meu pai me fez como gente e meu avô foi enterrado".

Sobre a especificidade do Xingu, esse fato nos mostra que os Kamayura habitavam a região muito antes de ela ser considerada território de ocupação nacional. E, nos faz lembrar que na amplitude do Brasil, nossas urbanidades sempre foram construídas por cima da identidade de diversas etnias indígenas. Ou seja, a construção do nosso país faz parte de uma colonização secular e contínua, divulgada em seus conceitos e ideais na formação educacional, no desejo de apagamento da história dos povos originários, da sua oralidade e da oportunidade de diálogo. E converge na falta de incentivo à pesquisa que venha aprofundar a discussão de como a constituição do "Estado Nação" tem sido realizada a partir da destruição das "nações" que viviam aqui.

Compreender esse mecanismo exploratório é entender a origem da invisibilidade estabelecida, mas também é sensibilizar sobre um percurso que matou e arrancou pessoas do seu território cultural, lugar onde tudo tem significado, trazendo consequências que dificilmente conseguirão ser ressarcidas. Como nos diz um dos líderes do movimento indígena brasileiro, Ailton Krenak (2015), se houve uma descoberta do Brasil pelos brancos em 1500, houve uma retomada da descoberta do Brasil pelos índios em 1970 e $1980^{\mathrm{xv}}$; e completa:

A que está valendo é essa última. Os índios descobriram que, apesar de eles serem simbolicamente os donos do Brasil, eles não têm lugar nenhum para viver nesse país. 
Terão que fazer esse lugar existir dia a dia, e fazer isso expressando sua visão do mundo, sua potência como seres humanos, sua pluralidade, sua vontade de ser e viver (KRENAK, 2015, p. 248).

Aqui faço uma pausa, pois lembro a palestra realizada por Ailton na USP/Leste no ano de 2017. Ele, após ter discursado sobre tantas injustiças, interrompeu a fala e disse: "essas coisas me deixam muito chateado, então eu preciso parar e cantar". Retirou um pequeno chocalho da sua bolsa e começou um canto. Assumindo a admiração pelo ato, faço o mesmo nesta escrita às vezes dura, também por seguir regras de convenção:

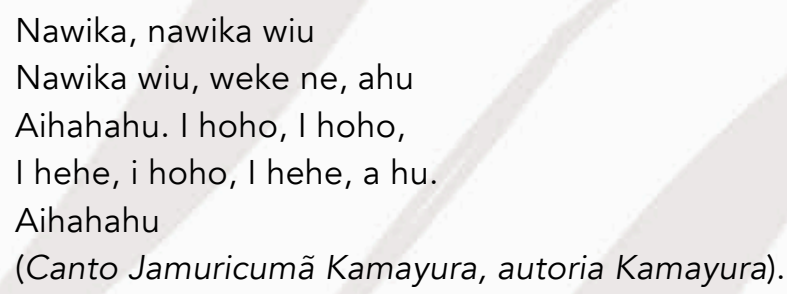

Respiro.

Em consequência da nossa formação e da falta de entendimento de como conceitos hegemônicos impõe saberes aos nossos corpos, que relatos como o meu (quando eu quis ir para aldeia) ou dos professores da aula mencionada acima, são ainda comuns de serem ouvidos em pleno século $X X$, após quinhentos e dezoito anos dessa terra ter sido denominada com o nome de uma mercadoria - como bem nos lembra Krenak (2015). E é por isso que considero esse o ponto inicial da minha pesquisa em arte cênica em relação aos indígenas. Primeiro porque o teatro é arte pela qual 
escolhi expressar, depois porque esse teatro que eu sempre interessei é como fala Fernandes (2008, p 19), uma produção artística preocupada com as exclusões sociais. Mas vou além, é lugar de questionamento contra um mundo de ambição mercantilista e espaço de emissão de significados. Visa uma expressão autônoma, pela qual entende o corpo como lugar de construção de conhecimento, valorizando a experiência da vida pessoal, no processo de criação e na relação com o público. Finalmente, porque foi a partir da noção da própria cegueira que eu quis sair da minha casa e trocar com os Kamayura na casa deles. Foi por meio dessa vivência de cinco anos na comunidade e de dezoito anos de pesquisa que eu passei a enxergar a complexidade daquele corpo/ser, assumi qual ponto de vista eu queria enxergar e comecei a ter a entendimento do tanto que o diálogo com os povos indígenas podem relativizar a noção colonizadora do saber, da arte, sobre corporeidade e a vida.

\section{A VIRADA NA CURVA DA EXPERIÊNCIA}

Costumo pilheriar que não é a proposta de uma pesquisa escrita e teórica que me leva a fazer uma investigação, mas que aquela é uma boa desculpa para concretizar algo imbricado no próprio desejo. Nessa costura, me identifico com o ator Eduardo Okamoto (2009, p 9) quando no seu doutoramento fala que o conhecimento teórico não foi mapa para a jornada ou indicador dos caminhos a serem seguidos, mas que o saber emergiu da 
caminhada, do ato: atuação. Um conhecimento que não se estuda só em livro, mas se reconhece no corpo, se advinha em si. Porém, nem sempre as trilhas são tão claras. Por isso que, como me ensina a oralidade do líder indígena Davi Kopenawa: "a gente fica ali, que nem namoro de onça, olhando de longe pra ver o que vai acontecer", eu rabisco a ideia de um modo de fazer, buscando mapear o percurso traçado, reconhecê-lo, para então seguir em frente.

Olhando assim de longe, vou identificando que se o primeiro movimento de ir para aldeia foi em busca de aproximar e conhecer aquela realidade, a subida seguinte foi a construção de um objetivo no campo atoral, que pretendia estudar a expressão daquele corpo para o teatro. Mas enquanto uma pesquisadora e atriz iniciante a minha entrada naquele espaço foi sendo realizada sem uma metodologia sistematizada a priori, ou seja, em um "caminho duvidoso, no qual a única pista que segui foi da ação, pois eu pensava que era preciso experimentar o que aquele corpo fazia para, quem sabe, aprender" (FIGUEIREDO, 2015, p 31). Naquele momento, aquele não-método fez com que o foco abrisse e, assim, eu comecei a realizar outras ações com a comunidade para além da investigação inicialmente pensada. Por outro lado, este fato fez com que eu pudesse experienciar a vida comunitária de forma ampla e em um tempo prolongado.

Então, ali estava uma mulher, uma pessoa, uma atriz que foi viver aquele jeito de ser. Na vida cotidiana, aprendendo o andar da 
roça e com o peso na cabeça, o andar em cima da canoa, banhos matinais, vespertinos, sons de ninar, formas da mulher assentar, do homem, da menina reclusa, do discurso, de matar pernilongo, de puxar a barriga para cima para não crescer, de pintar o corpo, cuidados consigo, de apontar com a boca, secar o cabelo, de tirar piolho, de agachar, de falar em tom baixo. Mas também, participando de rituais, cantando, dançando, conhecendo a língua (apesar de hoje estar menos fluente) e vivendo conflitos sociais, políticos, ambientais, em momentos de tristezas e alegrias íntimas, ouvindo histórias tão representativas daquele povo e se tornando família.

Toda essa vivência profunda, complexificou o entendimento em torno da vida Kamayura e passou a afetar sinestesicamente o meu ser, a noção de alteridade, reposicionando não somente a minha experiência, mas também paradigmas sobre conhecimento e corporeidade. Porque o que eu encontrei na aldeia foi uma existência preenchida de sentido, que imprime a sua forma, registra o seu lugar, a sua identidade, na qual os seus modos de fazer e as suas construções de sentido estão totalmente interligados, reelaborando-se em um movimento contínuo. Esse é um pensamento que se interliga a fala da professora Leda Martins (2002), que nos diz que os povos tradicionais nos seus simbolismos e cosmologias vivem e revivem a sua ancestralidade em oscilações dinâmicas, não apenas repetindo um hábito, mas também instituindo, interpretando e revisando o ato reencenado. Estes 
corpos possuem uma natureza meta-constitutiva, nas quais o fazer não suprime o ato de reflexão; mas o conteúdo imbrica-se na forma, a memória grafa-se no corpo, que registra e modifica dinamicamente.

Foi tendo em vista toda essa conjuntura embrenhada e marcada no meu corpo, que após ter saído da aldeia eu passei anos voltando para a comunidade, experimentando na prática de atuação e levantando os seguintes questionamentos: como eu poderia criar procedimentos de atuação sobre a vida indígena, em especial em relação ao corpo Kamayura? Mas também, o que seria essencial sublinhar, dentro da complexidade social e cultural que envolve a questão indígena, na realização de um espetáculo teatral?

Não com muita consciência, acabei inicialmente buscando responder a primeira pergunta. Assim, parti por uma trilha pela qual eu tentei entender ações, falas e gestos da corporeidade Kamayura enquanto "material" cênico. Eu fui sistematizando aqueles movimentos, desenhando, separando fotografias, sons, elaborando partituras, jogos de improvisação, de ritmo, de qualidade e jogos coletivos. Ao mesmo tempo, fui elaborando e realizando aulas, também inserindo essa experimentação na criação. E foi aqui, na diferença entre o resultado dos processos de ensino e a atuação relacionada com a minha experiência, que eu virei em uma curva o caminho da investigação.

que aconteceu foi que quando eu ensinava ou tentava ensinar esses movimentos indígenas, seja na criação teatral - tal 
como foi no processo do espetáculo Ode Marítima com os atores envolvidos na construção da cena do índio ${ }^{x v i}$ - ou em aulas e workshops lecionados, eu percebia um esvaziamento do fazer, uma falta de pertencimento em relação aos movimentos, uma ausência de terra e de sentido. Por outro lado, ao trazer essas referências da corporeidade Kamayura no meu exercício de atuação, elas se tornavam um ponto de partida que articuladas à minha subjetividade, adquiriam um tempo rítmico específico, preenchidas de detalhes, introduzindo características que não tinham sido anteriormente planejadas. Portanto, a relação entre o ensinar e o fazer, me levou à reflexão de que toda corporeidade encerra em si a potência da memória, que se dá no ato do fazer, na busca do como foi feito e no deixar o corpo responder sem o bloqueio de uma mente que quer controlar e entender tudo (RICHARDS, 2014).

Ora, o que está sendo falado é a retomada daquela noção de corporeidade, de um corpo-atriz que a partir da experiência do seu ser, reviveu artisticamente um conhecimento, reelaborando-o e instituindo-o criativamente. Como nos diz Leda (2002) "nas espirais do tempo, tudo vai e tudo volta". Essa é a virada na curva da experiência, quando o conteúdo foi inserido na forma e a forma tornou-se preenchida de sentido, isso por meio de um trabalho que demandou tempo, interesse, inteireza, houve a possibilidade de aproximar-se da condição singular, simbólica e complexa do corpo indígena ${ }^{\mathrm{xvii}}$. 
A experiência rememorada acima é, tal como nos diz Jorge Larrosa (2015), aquela que para acontecer é preciso um gesto de interrupção, de escuta, de atenção, do encontro com o outro, da necessidade de tempo e espaço. Nesse sentido, o autor se refere a uma experiência não como algo que possamos aprender ou modelo a ser repetido, mas como um acontecimento. Uma forma de deixarse afetar. Envolve, portanto, um engajamento no trabalho do ator que se deixa ser transformado pela experiência. É este - um corpo atravessado por afetividades - que interessa para esta indagação atoral e no lugar de possibilidade de criação em relação àquela corporeidade tão específica como a Kamayura. Com este compromisso que a pergunta passa a ser, não mais o que fazer a partir das formas, mimeses, jeitos daquele corpo; mas sim o que nessa experiência e relação tornou-se significativo em meu corpo de atriz.

\section{GAVIÃO DE DUAS CABEÇAS}

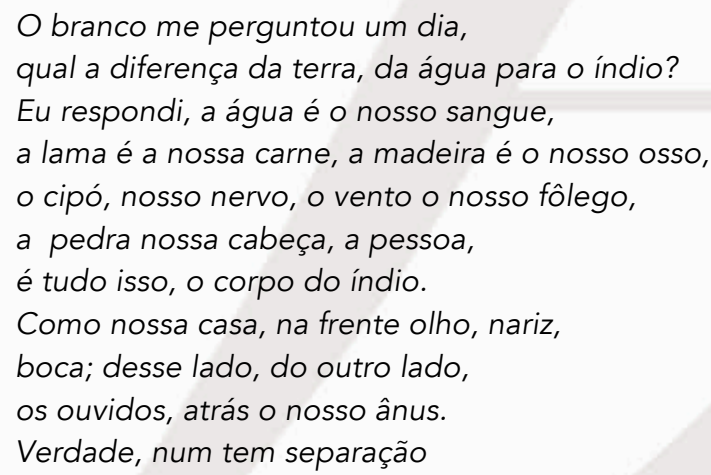

(Texto do espetáculo Gavião de duas cabeças, inspirado na fala dos líderes Ambrósio Guarani-Kaiowa - assassinado, e do falecido pajé Koka Kamayura). 
Aprendi lendo Jorge Larrosa (2015), que o lugar da paixão é ocupado por um sujeito passional que se expõe atravessando em um espaço indeterminado e perigoso, pondo-se nele à prova e buscando nele sua oportunidade e ocasião. Tenho a impressão que este é o lugar dos sonhadores que insaciáveis, vão abrindo picadas mesmo sabendo que essa é uma trilha sem fim. Digo isso porque três dias depois de quando defendi a minha escrita de mestrado e que se deu a partir dos anos de experimentação atoral e da vivência com os Kamayura, eu me jogo novamente para a sala de trabalho e como atriz tentando resolver a urgência, tão antiga, de criar um espetáculo que envolvesse a questão indígena. $\mathrm{O}$ engraçado é que entrei nesse novo e arriscado percurso acreditando que esta seria uma forma de fechar o ciclo sobre este assunto, tal como saliento no programa do espetáculo:

(...) Durante os 16 anos que passaram; entre os experimentos práticos e às vontades de fugir desse assunto, foi impossível desapegar do cheiro da aldeia, indigno ouvir tantos preconceitos vindos de olhares colonizados e a tatuagem marcada em meu braço só me fazia lembrar que era preciso morrer o desejo dessa pesquisa, cavar a própria tumba (FIGUEIREDO, CARNEIRO, 2016b).

Mal eu sabia que ao invés de cavar uma tumba, eu estava abrindo outras e profundas fissuras. Então, aquele era um momento em que eu havia entendido qual o lugar da atuação que acreditava em relação à corporeidade indígena. Isso mostrava que a pesquisa havia apontado o como, ou seja, de que era preciso uma relação de 
afetividade corporal, pessoal e atoral, que criassem conexões preenchidas de sentido no momento da atuação. Mas, por mais que eu tivesse me flagrado em atos de fuga, ainda era preciso - do ponto de vista amplo da investigação e agora um pouco mais consciente - responder a segunda pergunta que fiz após sair da aldeia: o que seria essencial sublinhar, dentro da complexidade social e cultural que envolve a questão indígena, na realização de um espetáculo teatral?

Do lugar de atriz, eu sabia que tinha a memória daquela vivência atravessada no meu ser, que tinha sistematizado formas de fazer e as tinha experienciado de forma espetacular por meio da cena do índio. Tornava-se preciso, então, continuar em uma produção no teatro que incentivasse e dialogasse com o conhecimento e a criatividade atoral. Nesse sentido que novamente procurei a diretora Juliana Pautilla, pois com ela eu tinha realizado vários processos de criação, inclusive a cena do índio, ela conhecia a minha história de vida e de pesquisa com os Kamayura e afinávamos em uma prática teatral voltada para realizações a partir de experimentações com o corpo.

Não tínhamos recurso financeiro e ainda não havia equipe técnica de criação. Trazíamos somente almejo e coragem de fazer de modo compartilhado o espetáculo. Como eu morava em São Paulo e Juliana em Belo Horizonte, para mim o processo se deu por meio de ensaios solitários, nos quais eu me filmava, assistia, editava o material de cena e quando achava algo interessante, eu gravava e 
mostrava para a diretora via "Youtube". Durante toda a criação, nós nos encontramos sete vezes em imersões e em sua maioria em momentos de apresentações públicas, seguidas de debates em vários espaços ${ }^{\mathrm{xviii}}$. Conseguimos estrear o espetáculo, por meio de uma campanha de financiamento coletivo, do Edital Cena Aberta de ocupação da Funarte/Sp e através de parcerias com profissionais de vídeo, luz, som, cenografia, figurino e design que conectavam com a realização ${ }^{\text {xix }}$.

Em relação à dramaturgia - e não estou falando somente do texto, mas sim da enunciação de sentido provocada na construção do espetáculo - eu e a direção assinamos juntas. Desde o início, eu acreditava que era imprescindível a presença de um olhar mais distanciado do que o meu, mas também entendia que existiam questões que somente os anos da experiência e estudos poderiam tocar. Mesmo porque havia a consciência de que esta era uma produção a ser realizada prioritariamente para um público não indígena e que o recorte não queria aprofundar sobre os aspectos da cultura em si. Distante disso, a idealização passava por um posicionamento político perante uma sociedade que não reconhece a existência diversa e étnica dos povos originários. E por isso havia a preocupação de não cairmos em um lugar comum, dado, didático sobre a obviedade da defesa em relação aos povos indígenas. Estávamos buscando uma realização que fizesse o público sentir e refletir sobre o próprio distanciamento. 
Nesse argumento da criação, fizemos a escolha de partir da minha memória corporal, sensitiva e discursada, por meio de experimentações e jogos de movimento, de espaço e improvisação, por meio de entrevistas que a diretora realizou comigo e de todos os registros imagéticos, escritos e gravados que possuo. Ali, buscávamos um material cravado na pele, as sensações de cheiros, o tempo dos fazeres, imagens rememoradas, histórias engraçadas, fortes, tristes, cantos, choros, saberes de trabalho, de alegria e dor. Estávamos escavando os momentos poéticos que transformariam a cena.

Por um viés político, também fizemos a opção de me perceber como uma pessoa não indígena que viveu nos dois contextos, a aldeia e a cidade, procurando identificar os preconceitos gerados por essa escolha, buscando entender o lugar que eu ocupava dentro da comunidade, as questões que envolvem o encontro com a alteridade e, igualmente, questionado as próprias ações enquanto colonialistas. Posso citar na dramaturgia, a minha fala como "atriz-Andreia"xx , revendo lugares que às vezes eu me colocava dentro da comunidade:

Nós criamos uma escola juntos. Os Kamayura queriam aprender a falar, ler e escrever em português. Também matemática. (Vira para o público) Não queriam escrever em língua própria. Eu queria. (Continua falando. Guarda o pincel por trás do painel central, vai em direção ao painel direito para colocar a cabaça ao lugar original). Eu queria que eles escrevessem na língua própria, eu queria que eles escovassem os dentes, eu queria que eles não ficassem tomando café e açúcar toda hora, eu queria que eles não comprassem biscoito doce recheado pra 
merenda, eu queria que as crianças jamais soubessem o que é coca-cola! Eu queria que eles não ficassem pedindo dinheiro, que eles não aceitassem fazer vídeos e fotos sem contrato, eu queria que os políticos do voto, da carteira de identidade, os fazendeiros do turismo, os projetistas de plantão ficassem longe da aldeia. O mais absurdo é que eu queria que eles guardassem o dinheiro, assim, poupassem dinheiro, no Banco do Brasil, pra projetos de sustentabilidade. (Ironizando a si mesma e constatando sua postura) Eu queria, eu queria, eu queria. Eu tinha aquela ideia, daí eu queria. Eu queria, eu queria um monte de coisas!

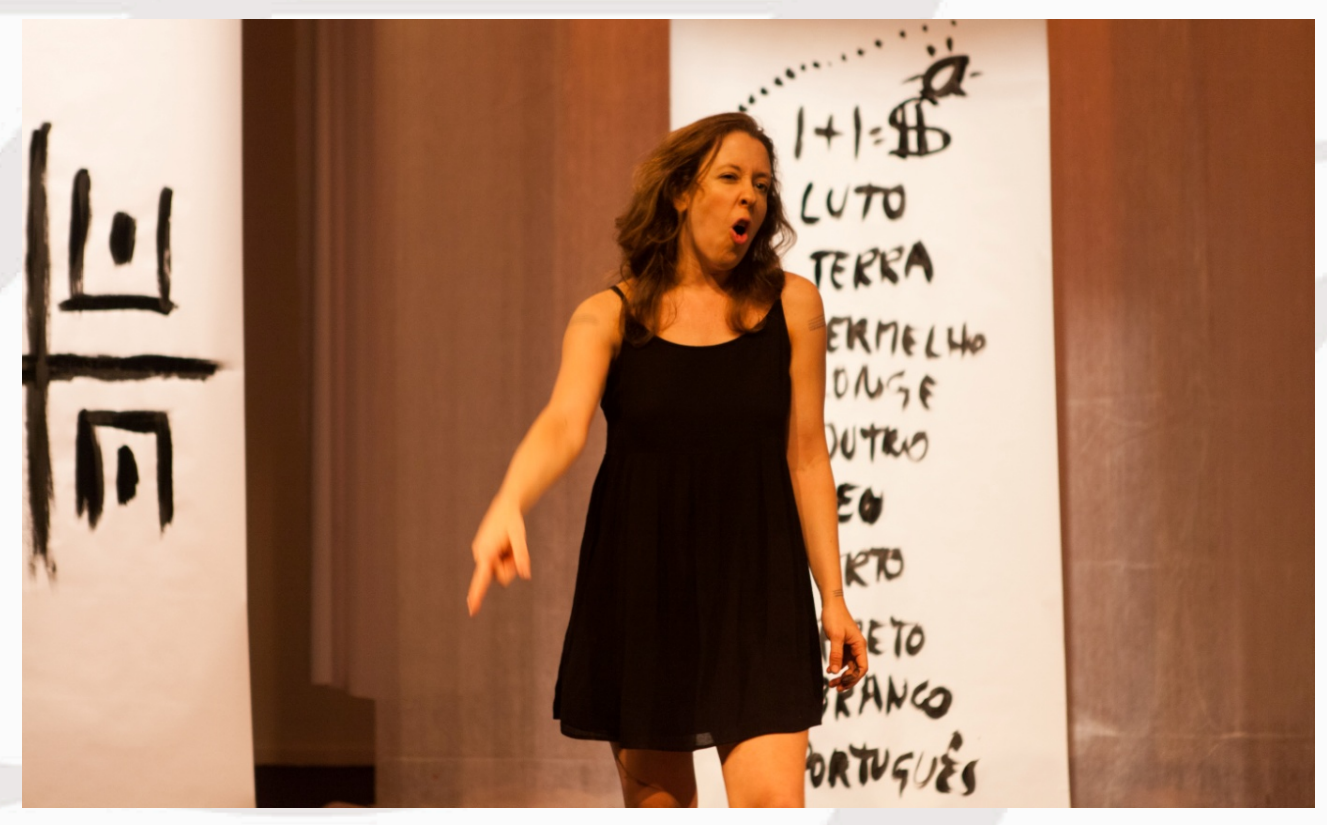

Espetáculo Gavião de Duas Cabeças. Foto: Fernanda

Também buscamos mostrar os sentidos que envolvem a noção de terra como ponto central da questão indígena no Brasil e de revelar mecanismos exploratórios da colonização utilizados até os dias de hoje. Como exemplo dessas construções que foram levantadas no espetáculo, cito: a imposição da escrita, do papeldinheiro ou do papel-escritura como forma de domínio e 
apropriação da terra. Os discursos políticos e autoritários, os chamamentos de intervenções militares na expulsão de indígenas dos seus territórios, como formas de abuso hegemônico, as referências estereotipadas como preguiçosos ou aqueles que usam celular, como formas de desconhecimento e preconceito, a ideia de índio genérico como homogeneização da diversidade, apagamento de suas histórias etc.

No levantamento deste material, foi feita uma investigação de discursos reais, tais como das militâncias dos líderes indígenas, Davi Kopenawa, Ailton Krenak, Raoni Krenakore, Sônia Guajajara, Kotok Kamayura, Mapulu Kamayura, Eupídio Pires, Ambrosio Guarani-Kaiowa. Da mesma forma, buscamos identificar as falas de vários congressistas, e acabamos por nos concentramos especialmente no discurso da senadora e representante da bancada agropecuária Katia Abreu ${ }^{x x i}$. Como exemplo dos sentidos que envolvem a terra e como foram abordados no espetáculo, elucido um fragmento do texto pelo o qual eu como "atriz-Kátia" apresento ironicamente o argumento de um projeto constitucional que tenta impedir a retomada de terras por indígenas, tendo como base o Estado de Direito e a defesa do progresso econômico:

Agora a questão indígena que nunca foi problema tão forte assim no Brasil, quando os índios pleiteavam as áreas da Amazônia, agora saem da Amazônia descem da Amazônia para o sul do país querendo às NOSSAS áreas de produção. Quer dizer, isso é só pra bobo, senhor presidente. Eu queria saber como que 800 índios arrumam dinheiro para ir para Belo Monte impedir que a usina seja construída? Isso está claro, transparente, cristalino que 
tem organismos internacionais financiando. Meia dúzia de índios, um tanto vagabundo pintado andando por aí, fazendo baderna, vandalismo. Belo Monte está longe do rio Xingu, o rio aguenta. A Natureza aguenta. A terra está aí para usufruirmos, para servir aos interesses do mercado (FIGUEIREDO e CARNEIRO, 2016a).

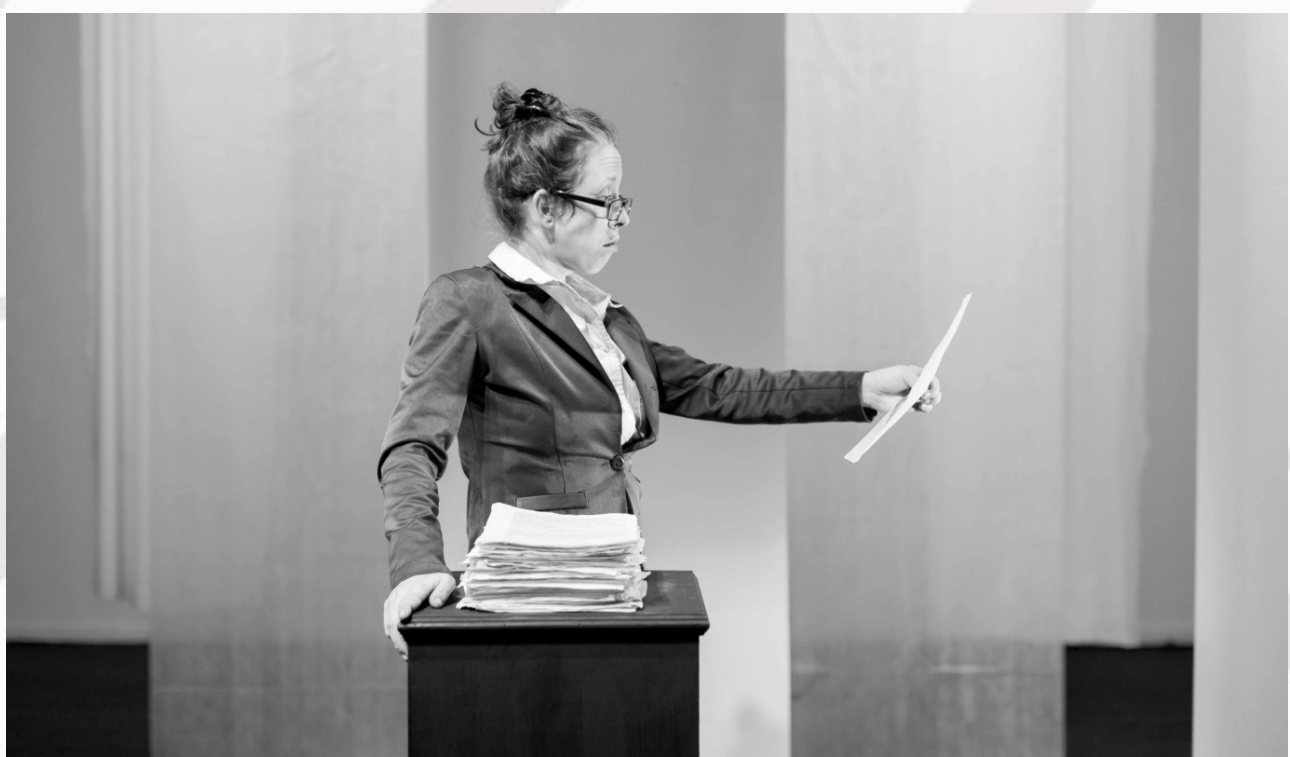

Espetáculo Gavião de Duas Cabeças. Foto: Fernanda

Em uma exposição inversa na cena, também mostro a seguinte fala que faço como "atriz-índia", na língua indígena Kamayura, que tem a tradução para o português projetada no cenário e é baseada no ponto de vista do líder Yanomami, Davi Kopenawa ${ }^{x x i i}$

Pemonetá ikatuiteá, fazendeiro apo, garimpeiro apo, mineração hidrelétrica a nite. Yaua je ne Paraná, yaua jene ata, ang ore opotaritea koyt. Je, tenote, napotaritéa mapam omanõa. Eu num quero morrer outra vez, ore oretaim omanoa 517 kwara awi. Ang’a erupi, ang`a erupi awite, ore, ore ka`a Brasil. Então, ang je ne problema aeteuat (FIGUEIREDO e CARNEIRO, 2016a). xxiii 


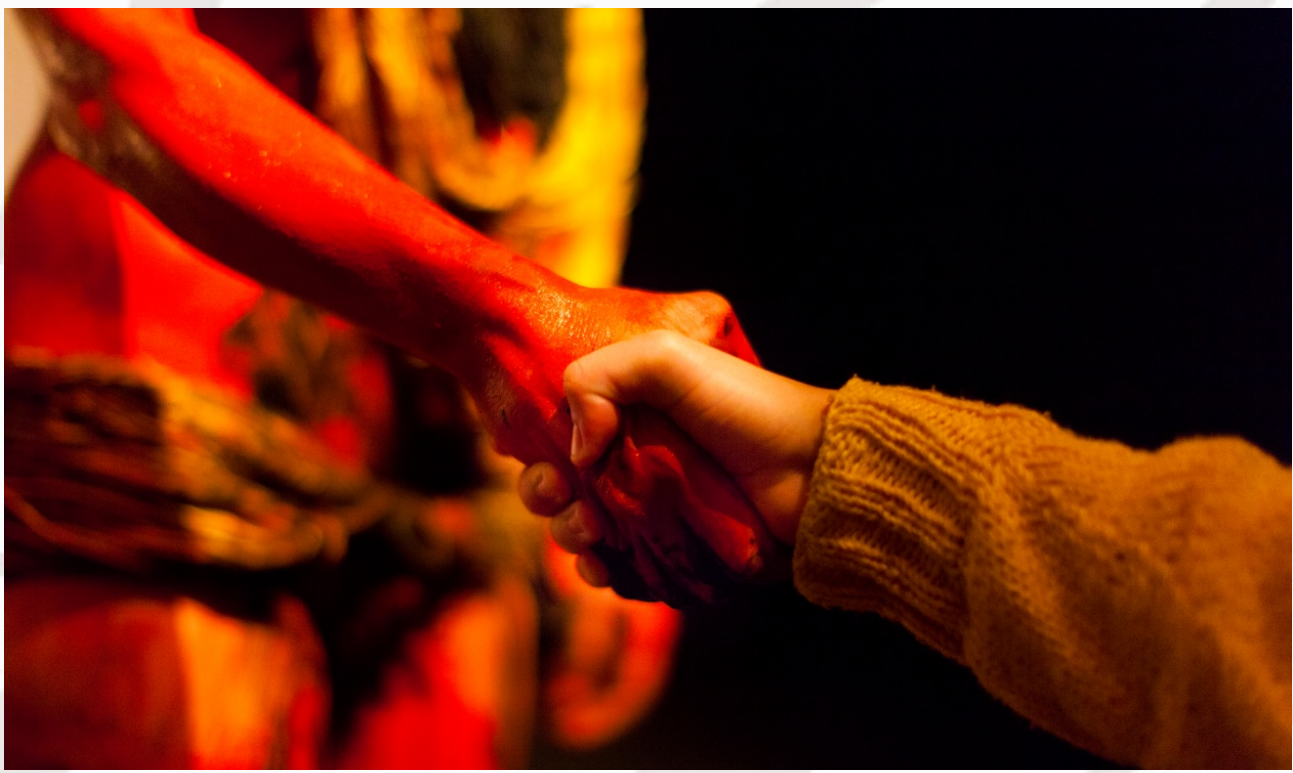

Espetáculo Gavião de Duas Cabeças. Foto: Fernanda Procópio

Essas opções acabaram por marcar a abordagem dramatúrgica a partir de um enfoque autobiográfico e documental. Tanto no nível cenográfico, videográfico, como na pesquisa sonora. Contudo é preciso dizer que eu nunca havia planejado o percurso autobiográfico por receio de que o espetáculo acabasse em um lugar psicológico e autocentrado. Foi no embate com a direção que eu fui percebendo que era preciso abrir minha própria experiência para o sentido que gostaríamos emanar. Era preciso ser eu mesma, me expor na sensação, na memória, no desejo de ser o outro, no posicionamento político, e também, como colonizadora. Hoje percebo que se esse espetáculo ainda resiste - sendo um teatro feito por não-indígenas sobre questões que envolvem a causa indígena - é porque o recorte dramatúrgico foi feito a partir do 
lugar da minha fala e das imbricações relacionada com a minha experiência.

Pontuo que em todo o processo de criação e durante várias apresentações convidamos profissionais indigenistas, antropólogos e militantes da área, seja do teatro ou envolvidos com os povos originários. Também, sempre convidamos lideranças indígenas para assistir e conversar sobre suas percepções. Apresentamos para um público Guarani na cidade de Dourados, apresentamos no pequeno palco do Acampamento Terra Livre de 2017 - maior encontro nacional indígena do Brasil realizado no gramado que fica em frente ao Congresso Nacional na cidade de Brasília (DF). Havia mais de 4000 indígenas de diferentes origens e etnias. Ainda, tivemos na plateia os líderes indígenas Ailton Krenak e Davi Kopenawa que assistiram e comentaram o espetáculo no último dia da temporada de 2017, na cidade de São Paulo.

Tenho de diferentes formas, tentado dialogar sobre a arte e a cultura como formas de resistência. E por esse viés, procurado entender como representantes de diferentes etnias pensam sobre o teatro contemporâneo e como enxergam pessoas que não são indígenas realizando espetáculo que tratam de assuntos que os envolvem. Fiz exatamente essa pergunta para Davi Kopenawa, como mediadora de uma palestra voltada para um público jovem de teatro $^{\mathrm{xxiv}}$. Davi deu a seguinte resposta:

Eu acho que quando vocês, que não são índios, falam sobre a questão dos índios, vocês fazem com que as pessoas olhem para mim. Enxerguem quem eu sou. Nós 
não somos diferentes não, somos a mesma pessoa, branco, negro, índio, tudo igual. A verdade é que estamos lutando pela mesma coisa. Pela nossa vida, nós. É isso que é importante. (FIGUEIREDO, 2018).

É com essa fala que vou terminando a escrita. Porque nela eu identifico a inerência do que buscava "sublinhar" em um espetáculo sobre a questão indígena. Havia ali uma luta real e simbólica contra o gavião de duas cabeças, uma ave que segundo a mitologia Kamayura, devora os índios mesmo depois da morte, acabando para sempre com a sua existência. Essa luta tornou-se para nós, na criação teatral, a representação de um sistema capitalista que destrói a natureza, apaga os indígenas e seus conhecimentos, pela ambição de um progresso desmedido e o desejo pela mercadoria. Hoje entendo que aquela pergunta que eu faço ao sair da aldeia, tratava de algo muito maior, como Davi fala; sobre nós e sobre nossa vida. Acho que é isso que esta pesquisa sempre indagou, sobre as diferentes propostas de existência e sobre o que é essencial para vivermos.

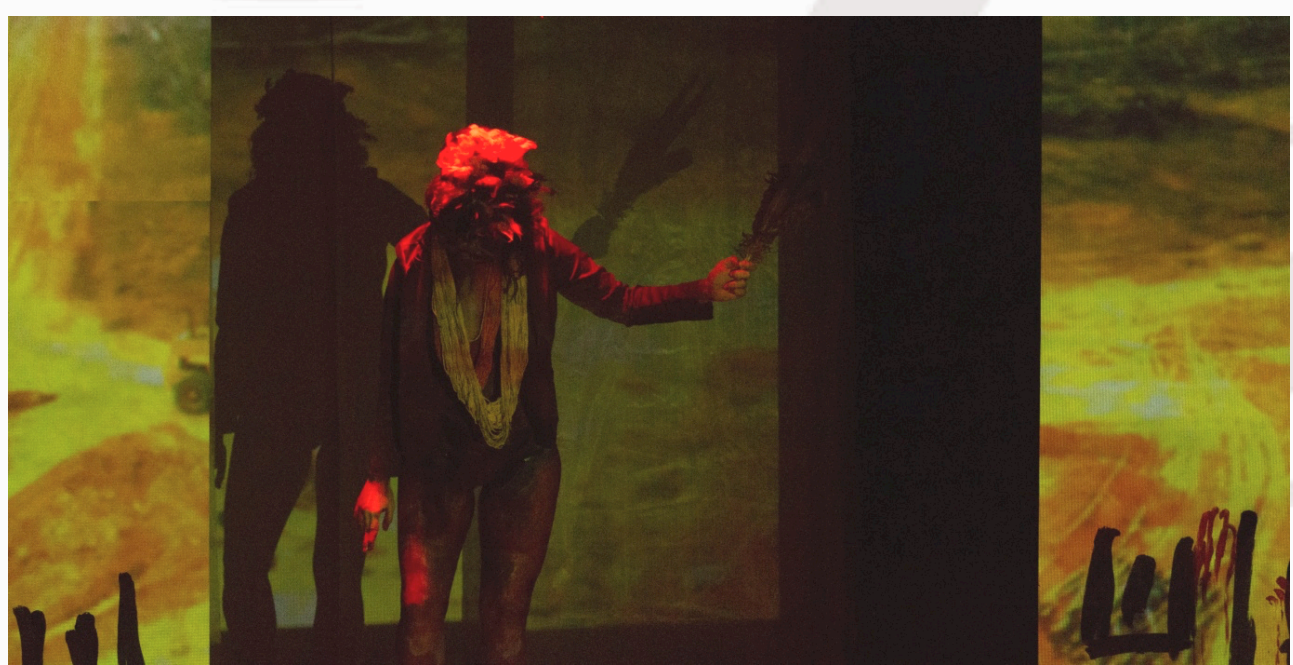

Espetáculo Gavião de Duas Cabeças. Foto: Fernanda Procópio 


\section{OUTRAS FISSURAS.}

Quando retomo o "olhar da onça" e observo o caminho que ficou atrás; vejo tantas pegadas, árvores passadas, frondosas, folhas, galhos e espinhos. Estar dentro de uma floresta fechada é como estar debaixo da água, não existe silêncio, mas uma vida própria tudo está vivo. E foi vivendo e olhando que eu percebi que aquele não-método declarado, assumido no momento que eu entrei na aldeia, foi justamente o que me possibilitou conseguir defender a convivência e a afetividade enquanto uma forma de pensar e fazer. Hoje, distingo um percurso de pensamento naquilo que eu não havia assumido enquanto método, reconhecendo uma metodologia de investigação que se dá por meio da experiência vivida.

Sim, um procedimento traçado na existência, descrito, elucubrado, que reconhece uma produção de conhecimento e se deixa transformar. Acontecimentos, diria Jorge Larrosa. Demasiados ao ponto de implicarem em mudança de paradigma sobre o que é o saber, sobre a noção de corporeidade, sobre o estigma da colonização, sobre o essencial para viver, tendo o saber étnico indígena e atoral enquanto referência. Foram essas curvas apresentadas no tempo e espaço que apontaram as trilhas, que me fizeram vislumbrar a afetividade corporal preenchendo o corpo da atuação e sublinharam na criação do espetáculo as relações com a natureza e o que queremos para a vida.

Por isso um teatro poético-político, que por meio da estética vai tomando posição. Acentua a necessidade de um ator 
que se joga contra o muro, que se expõe, abrindo feridas e de uma encenação que costura os sentidos, buscando tocar o outro que chega ali apenas para assistir. Não há credulidade, mas resistência de uma arte que se vê como possibilidade. Uma re-existência aprendida na coletividade, no ato, pelo desejo e compromisso, na reverência de um corpo que vive e revive a sua existência, artística, ancestral, imponente a tantos massacres que foram submetidos.

Daí a importância de assumir para o teatro toda abrangência que as relações étnicas e políticas podem possibilitar. Uma procura que traz esse envolvimento pode expandir o que entendemos sobre a formação do nosso país, ajuda a perceber a invisibilidade social, a violência e a injustiça que envolve a colonização e os povos originários. Ou seja, possibilita construir posição crítica no sujeito que irá produzir expressão subjetiva na arte. Também porque amplia a noção de produção de saber no entendimento da ancestralidade e da dinâmica cultural. Nesse sentido, o encontro com os povos indígenas pode expandir o que o artista percebe enquanto corporeidade, não só esteticamente, mas na própria percepção atoral, biográfica, dos sentidos, fazendo-o reconhecer sua autonomia de criador. O confronto da própria humanidade com a riqueza de uma existência outra, potencializa a descoberta de si, a expressão artística e a sensibilização social.

Por causa dessa relevância que vejo este momento, no qual pesquisas do campo teatral têm voltado para o Brasil e se perguntado sobre decolonização, como urgente e necessário. 
Paralelamente, escuto líderes indígenas, como o próprio Davi Kopenawa e Ailton Krenak, que de forma atual fazem discursos indignados sobre os contínuos mecanismos da colonização. Claro, se há uma necessidade nossa de reconsideramos as nossas referências corporais e coloniais, não há o porquê esses líderes tentarem buscar outros parâmetros visto o que é inerte na vida deles. São corpos originários do país, não-fragmentados e que vivem a arte no seu cotidiano, seja ele ritualístico ou não. É assim que me arrisco ávida por outro começo: como nós do teatro e dentro do Brasil queremos falar de descolonização sem dialogar com os povos originários?

Novas e profundas fissuras.

\section{REFERÊNCIAS}

FÉRAL, Josette. Por uma poética da performatividade: o teatro performativo. Sala Preta, São Paulo: USP, v.8, p. 197-210, nov. 2008.

FERNANDES, Silvia. Teatralidade e performatividade na cena contemporânea. Repertório: Teatro e Dança, Salvador, v.14, n. 16, p. 11-23. 2011.

FIGUEIREDO, Andreia. Palestra do líder Davi Kopenawa. (Mediação Andreia Duarte). Cadernos de anotação. SP Escola de Teatro. 2018.

FIGUEIREDO, Andreia. O instante da cena do índio, a expressão poética de uma experiência. Local: Programa de Pós Graduação/Universidade Federal de Minas Gerais, 2015. 120 p. Dissertação (Mestrado em Arte). 
FIGUEIREDO, Andreia. CARNEIRO, Juliana. Gavião de duas cabeças. (Texto) 2016 a.

FIGUEIREDO, Andreia. CARNEIRO, Juliana. Gavião de duas cabeças. (Programa) 2016b.

FIGUEIREDO, Andreia. CARNEIRO, Juliana. Gavião de duas cabeças. (Projeto). 2017.

INSTITUTO SOCIOAMBIENTAL. Povos Indígenas no Brasil: 2011 - 2016. (Editores gerais: Beto Ricardo e Fany Ricardo). São Paulo: Instituto Socioambiental, 2017.

INSTITUTO SOCIOAMBIENTAL. Almanaque Socioambiental Parque Indígena do Xingu 50 anos. São Paulo: Instituto Socioambiental, 2011.

KAMAYURA, Tacumã; KAMAYURA, Kanutary. Moroneta Kamayura: histórias Kamayura. Organização Andreia Duarte. Belo Horizonte: Literaterras; FALE/UFMG, 2013.

KRENAK, Ailton. Ailton Krenak. Org. Sérgio Cohn. $1^{\text {a }}$ Ed. Rio de Janeiro: Azougue, 2015. P 264.

KOPENAWA, Davi; ALBERT, Bruce. A queda do céu: Palavras de um xamã Yanomami. Trad. Beatriz Perrone. $1^{\text {a }}$ edição. São Paulo: Companhia das Letras, 2015.

LARROSA, Jorge. Tremores, escritos sobre experiência. Belo Horizonte: Autêntica, 2015.

MARTINS, Leda Maria. Performances do tempo espiralar. In: RAVETTI, Graciela; ARBEX, Márcia. (Orgs.) Performance, exílio, fronteiras: errâncias territoriais e textuais. Belo Horizonte: UFMG, 2002. p. 69-91.

MARTINS, Leda Maria. A oralitura da memória. In: FONSECA, Maria N. S. (Org). Brasil Afro-Brasileiro. Belo Horizonte: Autêntica, 2000. 
OKAMOTO, Eduardo. Dramaturgia de ator na intracultura. 2009. Dissertação (Doutorado em Artes) - Instituto de Artes, Universidade Estadual de Campinas, Campinas, 2009.

RICHARDS, Thomas. Trabalhar com Grotowski sobre as ações físicas. São Paulo: Perspectiva, 2014.

RODRIGUES, Graziela. Bailarino pesquisador intérprete, processo de formação. Rio de Janeiro: Funarte, 2005.

TAYLOR, Diana. O arquivo e o repertório: performance e memória cultural nas Américas. Belo Horizonte: UFMG, 2013.

VILLAS BOAS, Orlando. A marcha para o oeste. $5^{\mathrm{a}}$ ed. São Paulo: Globo, 1994.

\section{SITES}

YOUTUBE. Davi Kopenawa sobre PEC 215. Disponível em:

https://www.youtube.com/watch?v=bsRjdpXz140. Acesso 25 ago. 2017.

YOUTUBE. Kátia Abreu sobre projeto que quer proibir demarcação de terras indígenas. Disponível em: https://www.youtube.com/watch?v=y2278Nd_11E. Acesso em: 26 set. 2017.

MUNDURUKU, Daniel. Índio é invenção total, folclore puro. Disponível em:

https://www.geledes.org.br/daniel-munduruku-indio-e-invencaototal-folclore-puro/. Acesso em 27 ago. 2017.

IBGE. Censo 2010: população indígena é de 896,9 mil, tem 305 etnias e fala 274 idiomas. Disponível em: 
https://censo2010.ibge.gov.br/noticias-

censo?busca $=1 \& \mathrm{id}=3 \&$ idnoticia $=2194 \& \mathrm{t}=$ censo-2010-poblacao-

indigena-896-9-mil-tem-305-etnias-fala-274\&view=noticia. Acesso

em: 29 de março de 2018.

SP ESCOLA DE TEATRO. Palestra Davi Kopenawa (mediação
Andreia
Duarte).
Disponível
em:

http://www.spescoladeteatro.org.br/tag/davi-kopenawa. Acesso em: 29 de mar. 2018.

\section{NOTAS}

"A identidade genérica "índio" aborda uma discussão levantada por representantes dos povos originários, por ser uma denominação que carrega uma estratégia enfraquecedora no reconhecimento social e das suas identidades étnicas. Ver as reflexões de Ailton Krenak (2015) e o pensamento do Daniel Munduruku disponível em: $\quad$ https://www.geledes.org.br/daniel-munduruku-indio-e-invencao-total-folclore-puro/. Acesso em: 27 ago. 2017.

ii O Parque Indígena do Xingu é a maior reserva indígena do Brasil e localiza-se no estado do Mato Grosso. Para saber mais ver: INSTITUTO SOCIOAMBIENTAL, 2011.

iii Discuto na dissertação meus processos atorais a partir da experiência na aldeia, do reconhecimento do saber corporal Kamayura e da criação da "cena do índio" do espetáculo "Ode Marítima", dirigido por Juliana Pautilla (Premio Myriam Muniz, 2012). Ver: FIGUEIREDO, 2015.

iv Espetáculo solo, com direção de Juliana Pautilla e estreia em julho de 2016.

v Noções que dialogam com autoras como Leda Martins (2002), Silvia Fernandes (2011), Josette Ferral (2008), Diana Taylor (2013), dentre outras.

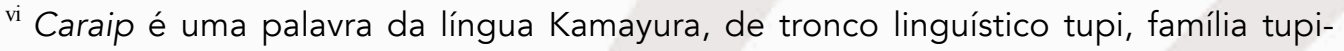
guarani, e significa aquele que não é indígena.

vii Para saber sobre as etnias que se encontram no território brasileiro ver: POVOS INDÍGENAS NO BRASIL, 2017.

viii Ver: IBGE. Acesso em: 29 de março de 2018.

ix IDEM. 
x Toda literatura relacionada aos povos do Xingu e aos Kamayura, é condizente em dizer que o primeiro contato dessas populações com agentes do mundo externo que se tem registrado historicamente ocorreu em 1884, por meio da expedição de Karl von den Steinen (Ver: FIGUEIREDO, 2015).

${ }^{x i}$ IDEM, p 40.

xii Na época denominado Parque Nacional do Xingu (1994, VILLAS BOAS, p 613).

xiii Cauaip é uma palavra Kamayura que significa índio.

xiv Ver: KAMAYURA, Tacumã; KAMAYURA, Kanutary. 2013.

${ }^{x v}$ Ailton refere a um período em que indígenas de diferentes etnias lutavam por representatividade em lugares de poder e comunicação, levando voz sobre a situação de massacre que vinham sofrendo durante todos os séculos de invasão. Ver: KRENAK, 2015.

xvi A "cena do índio" foi construída dramaturgicamente pelo viés da colonização, com duas figuras simbólicas uma mulher índia e um homem-branco-colonizador. A encenação e o trabalho de ator foram feitos a partir das relações sensitivas com a natureza e com a musicalidade, a fala, os cantos, o gesto e movimentos vieram a partir da minha pesquisa com os Kamayura.

xvii Neste ponto, considero importante o diálogo com a pesquisa prática e teórica realizada pela pesquisadora Graziela Rodrigues. Para saber ver: RODRIGUES, 2005.

xviii A produção foi realizada a partir de parcerias e mostras working progress, apresentando resultados da criação, com debates em vários lugares e instituições: "Primavera nos Museus" (Tiradentes,MG); "Espaço Esquyna" (BH, MG); Funarte (SP); Festival Cenas Breves (Manaus, AM); Teatro de Arena Eugênio Kusnet (SP).

xix Foi imprescindível a participação de criadores como Natália Machiavelli e Daniel Carneiro na criação do vídeo, Fernanda Guedella e Ronei Novais na criação da luz, Carlinhos Ferreira na trilha, Alice Stamato na direção e produção de arte, Daniel Carneiro na criação gráfica. E os parceiros de operação técnica como Bruno Carneiro e Ronei Novais, de registro fotográfico e em vídeo, como Robson Timóteo, Daniel Carneiro e Fernanda Procópio.

xx Tenho tomado à opção de me inserir como atriz, porque essa é uma cena conectada com um teatro performativo que não pretende a construção de personagem. Ali sou eu em todo o tempo, entrando em minhas vivências e retornando para o momento real do espetáculo.

×xi Ver: YOUTUBE. Kátia Abreu sobre projeto que quer proibir demarcação de terras indígenas. Acesso em: 26 set. 2017. 
xxii Ver YOUTUBE. Davi Kopenawa sobre PEC 215. Acesso em: 25 ago. 2017.

xxiii Tradução: Vocês criam o que não presta, fazendeiro, garimpeiro, mineração, hidrelétrica. Suja o nosso rio, suja os nossos lugares, isso é o que nós não queremos. Eu principalmente, eu não quero, morrer outra vez. Eu num quero morrer outra vez, como nós morremos ha 517 anos passados. Isso aqui tá retornando, tá retornando como que invadiu nosso, o nosso Brasil, então esse nosso problema de verdade. Ver: FIGUEIREDO, CARNEIRO.2016a.

xxiv Ver: SP ESCOLA DE TEATRO. Palestra Davi Kopenawa (mediação Andreia Duarte). Acesso em: 29 de mar. 2018.

*Andreia Duarte é atriz, pesquisadora, professora e produtora em artes cênicas. Doutoranda em Teatro da ECA/USP com pesquisas sobre descolonização a partir de referenciais da vida indígena e o teatro contemporâneo de resistência. Já participou como atriz de diferentes espetáculos, atua no solo Gavião de duas cabeças (direção Juliana Pautilla) e está em processo de criação com a diretora Lili Monteiro.

Artigo Submetido em: 04/04/2018

Aprovado em: 15/07/2018 